\title{
A NECESSIDADE DE RECONHECIMENTO E OS LIMITES DE UMA TEORIA LIBERAL DA JUSTIÇA
}

\author{
THE NEED FOR RECOGNITION AND THE LIMITS OF A LIBERAL THEORY OF \\ JUSTICE
}

\author{
LA NECESIDAD DE RECONOCIMIENTO Y LOS LÍMITES DE UNA TEORÍA \\ LIBERAL DE LA JUSTICIA
}

\author{
ERNANE SALLES DA COSTA JUNIOR \\ https://orcid.org/0000-0002-0088-6556 / http://lattes.cnpq.br/2666464264432207 / profernanesalles@gmail.com \\ Universidade Federal de Minas Gerais, UFMG. \\ Belo Horizonte, MG, Brasil.
}

\begin{abstract}
RESUMO
O presente artigo busca apresentar, à luz das reflexões de Honneth, as críticas e os limites de uma teoria da justiça liberal. Seu objetivo geral é o de demonstrar que a textura da justiça não é uma dedução de ordem abstrata, mas, ao contrário, está ancorada em relações sociais intersubjetivamente reconhecidas que são constituídas de práticas perpassadas de conteúdo moral. Para tanto, são analisados, primeiro, os componentes de uma teoria liberal da justiça a partir do pensamento de John Rawls. Feito isso, os pilares do liberalismo são submetidos a um exame crítico. Em seguida, o percurso de Honneth é apresentado a fim de traçar respostas às limitações e insuficiências da matriz liberal. A conclusão é no sentido de repensar a justiça para além da dimensão abstrata de modo a evidenciar a necessidade de reconstrução crítica dos fragmentos de normas e princípios morais e políticos já inscritos, ainda que parcialmente, na própria realidade social como processo de aprendizado social ético-normativo de longo prazo. Do ponto de vista metodológico, a pesquisa se sustenta com base na teoria crítica e é basicamente bibliográfica.
\end{abstract}

Palavras-chave: Axel Honneth. John Rawls. Liberalismo. Reconhecimento. Teoria da justiça.

\begin{abstract}
The present article seeks to present, in the light of Honneth's thought, the criticisms and limitations about a theory of liberal justice. The main objective of this research is demonstrate that the texture of justice is based on intersubjectively recognized social relations that are constituted of practices with moral content. For that, first, the components of a liberal theory of justice are analyzed based on the arguments of John Rawls. After this, the pillars of liberalism are subjected to a critical examination. Then, Honneth's theory is presented in order to draw answers to the limitations and inadequacies of the liberal matrix. The conclusion is to rethink justice beyond the abstract dimension, in order to highlight the need of a critical reconstruction of the fragments of moral and political norms and principles already subscribed, even though partially, in the social reality itself as a long-term process of ethicalnormative learning. From the methodological point of view, the research is based on critical theory and is basically bibliographical.
\end{abstract}

Keywords: Axel Honneth. John Rawls. Liberalism. Recognition. Theory of justice. 


\section{RESUMEN}

El presente artículo busca presentar, a la luz de las reflexiones de Honneth, las críticas y los límites acerca de una teoría de la justicia liberal. El objetivo general de esta investigación es demostrar que la textura de la justicia está anclada en relaciones sociales intersubjetivamente reconocidas que están constituidas de prácticas con contenido moral. Para ello, se analizan, primero, los componentes de una teoría liberal de la justicia a partir del pensamiento de John Rawls. Hecho esto, los pilares del liberalismo son sometidos a un examen crítico. A continuación, el recorrido de Honneth se presenta a fin de buscar respuestas a las limitaciones e insuficiencias de la matriz liberal. La conclusión es en el sentido de repensar la justicia más allá de la dimensión abstracta, de modo a evidenciar la necesidad de una reconstrucción crítica de los fragmentos de normas y principios morales y políticos ya inscritos, aunque parcialmente, en la propia realidad social como proceso de aprendizaje social ético-normativa a largo plazo. Desde el punto de vista metodológico, la investigación se sustenta con base en la teoría crítica y es básicamente bibliográfica.

Palabras clave: Axel Honneth. John Rawls. Liberalismo. Reconocimiento. Teoría de la justicia.

\section{SUMÁRIO}

INTRODUÇÃO; 1 BASES DE UMA TEORIA LIBERAL DA JUSTIÇA; 2 UMA ANÁLISE CRÍTICA DOS ELEMENTOS DE UMA TEORIA LIBERAL DA JUSTIÇA; 3 O MODELO ALTERNATIVO DE HONNETH: NO CAMINHO DE UMA REATUALIZAÇÃO INDIRETA DA FILOSOFIA DE HEGEL; CONCLUSÃO; REFERÊNCIAS.

\section{INTRODUÇÃO}

O debate contemporâneo em torno do conceito de justo passa pela construção de uma teoria da justiça capaz de fornecer uma orientação filosófica e moral para a práxis política. Especialmente por volta da década de 80, esforços filosóficos foram empreendidos na fundamentação de um conceito apropriado de justiça que oferecesse ideias teóricas e pontos de referência pertinentes para a negociação política de objetivos e programas. Nos termos em que o debate foi colocado, operou-se uma dicotomia em relação à forma como as instituições e as normas deveriam ser concebidas, o que abriu caminho para uma disputa de sentido sobre a concepção de justiça. De um lado, estavam os "liberais”; de outro, os "comunitaristas".

Grande parte da filosofia moral recente concentra-se em disputas acerca da posição relativa dessas duas diferentes ordens de normatividade. ${ }^{1}$ De um modo geral, os “liberais" teriam como pretensão justificar as instituições e as normas com base na ideia de que demandas de justiça estão acima das reinvindicações de vida ético-social ${ }^{2}$, de forma a servir como critério crítico para a sociedade. Essa primeira posição afirmaria, portanto, que as normas e princípios universalmente vinculantes transcendem o contexto particular das práticas e das instituições políticas palpáveis.

\footnotetext{
${ }^{1}$ FRASER, Nancy. Reconhecimento sem ética. Lua Nova, v. 70, n. 1, 2007, p. 104.

2 FRASER, Nancy. Reconhecimento sem ética. Lua Nova, v. 70, n. 1, 2007, p. 104.
} 
Trata-se de pensar uma concepção mais abstrata de "justiça" que, ao desvincular-se das tradições e determinações históricas específicas, possa fornecer uma normatividade que seja imparcial e impessoal. O político é aqui compreendido a partir da posição do sujeito autônomo e racional apto a construir padrões normativos que fornecem um aporte crítico à própria tradição. Tal perspectiva remonta ao legado kantiano de uma teoria fundada na moral deontológica, associada de modo mais direto à racionalidade.

Em sentido oposto estariam os "comunitaristas", que teriam como preocupação um auto esclarecimento acerca de quais seriam as tradições que constituem internamente a sociedade. Com base nessa segunda posição, as normas e princípios que regem as instituições sociais seriam imanentes ao contexto da própria práxis política. A justiça, nessa lógica, estaria atrelada aos contextos da comunidade, ou melhor, à sua história, tradição, práticas e valores que formam o horizonte normativo para a constituição da identidade de seus membros. ${ }^{3}$ Os comunitaristas compartilhariam uma desconfiança em relação à moral abstrata, pois partem da posição de um sujeito localizado numa comunidade histórica organizada em torno da ideia de bem comum em meio aos seus costumes e tradições. Esse ponto de vista remonta à tradição aristotélica de uma ética teleológica. ${ }^{4}$

Especialmente nas últimas décadas, a discussão que se travou entre liberalismo e comunitarismo não se caracteriza mais pela rigidez das distinções, pois experimentou as insurgências de diversas teorias que procuraram articular o ponto de vista imparcial da justificação normativa com as exigências mais concretas de ancoramento dos princípios de justiça. ${ }^{5}$ Dentre as propostas de superação da dicotomia, destaca-se a posição de Axel Honneth, na medida em que procura dar ênfase às práticas e instituições históricas concretas que possibilitam a autorrealização do indivíduo em situações de vulnerabilidade social, a partir de uma justificação normativa que transcende tais contextos específicos.

\footnotetext{
3 WERLE; Denilson Luis; MELO, Rúrion Soares. Introdução: Teoria crítica, teorias da justiça e a "reatualização" de Hegel. In: HONNETH, Axel. Sofrimento de Indeterminação. Uma reatualização da filosofia do direito de Hegel. São Paulo: Editora Singular, Editora Esfera Pública, 2007. p.18.

${ }^{4}$ Essa tradição engloba autores tão diversos como Michael Walzer, Alasdair Macintyre e Charles Taylor,. Para uma visão detalhada da particularidade das teorias desses autores (o que não corresponde objeto da análise dessa pesquisa), ver WALZER, Michael. Esferas da Justiça. Uma Defesa do Pluralismo e da Igualdade. São Paulo, Martins Fontes, 2003; MACINTYRE, Alasdair. Justiça de Quem? Qual Racionalidade? São Paulo: Loyola, 1991; TAYLOR, Charles. As Fontes do Self. A Construção da Identidade Moderna. São Paulo: Loyola, 1997.

5 WERLE; Denilson Luis; MELO, Rúrion Soares. Introdução: Teoria crítica, teorias da justiça e a "reatualização" de Hegel. In: HONNETH, Axel. Sofrimento de Indeterminação. Uma reatualização da filosofia do direito de Hegel. São Paulo: Editora Singular, Editora Esfera Pública, 2007. p.18.
} 
O diagnóstico de Honneth é de que as soluções liberais, tributárias de uma atualização de Kant, dominaram a pauta do debate sobre as teorias da justiça nos dias atuais, em detrimento das propostas de cunho comunitarista. Em razão disso, começa a se propagar novamente o antigo mal-estar de um paralelismo da filosofia política em relação ao agir político ${ }^{6}$; um hiato parece se aprofundar entre teoria e práxis. Esse distanciamento crescente entre teoria filosófica da justiça e práxis política é resultado do próprio pensamento liberal dominante, que formula princípios normativos num nível tal que se torna impossível derivar uma orientação para ação política ${ }^{7}$.

No entanto, os esforços do comunitarismo, de tentar superar a teoria da justiça dominante, embora voltem-se para a realidade social, não deram um passo adicional na formulação de uma base crítica consistente às próprias tradições e instituições políticas: o comunitarismo contentou-se apenas em reproduzir as tradições ao invés de caminhar para a sua apropriação crítica ${ }^{8}$. Honneth pretende, então, superar esse dilema entre liberalismo e comunitarismo ao desconstruir as premissas sob as quais as teorias liberais da justiça estão sustentadas, de modo a permitir seu exame crítico. Sem, contudo, cair num comunitarismo conservador, ele procura operar uma reconstrução tendo como base a normatividade já inscrita historicamente nas práticas intersubjetivas e nas instituições políticas, a fim de sustentar uma teoria crítica da justiça social ${ }^{9}$.

\footnotetext{
${ }^{6}$ HONNETH, Axel. A textura da justiça: sobre os limites do procedimentalismo moderno. Civitas, Porto Alegre, v.9, n.3, p. 345-368, set.-dez. 2009.

7 HONNETH, Axel. A textura da justiça: sobre os limites do procedimentalismo moderno. Civitas, Porto Alegre, v.9, n.3, p. 345-368, set.-dez. 2009.

${ }^{8}$ É preciso reafirmar "a importância da liberdade e capacidade dos indivíduos de distanciar-se das práticas e das estruturas culturais para poder formar, revisar e reformar suas crenças acerca dos significados e dos planos de vida. Nesta concepção, o processo de autodescobrimento, a consciência e o reconhecimento das várias ligações e pertenças culturais - tão valorizados pelos comunitaristas -, não substitui ou impede que os indivíduos exerçam sua autonomia, julgando os propósitos e obrigações herdados”. COSTA, Sérgio; WERLE, Denilson Luís. Reconhecer as diferenças: liberais, comunitaristas e as relações raciais no Brasil: In: AVRITZER, Leonardo e DOMINGUES, José Maurício (orgs). Teoria social e modernidade no Brasil. Belo Horizonte: Ed. UFMG, 2000.

9 Uma aplicação mais prática dessa proposta de reconstrução normativa (que não é nosso objetivo no presente texto) foi elaborada, por mim, na obra COSTA JUNIOR, Ernane Salles. Constitucionalismo do atraso. Belo Horizonte: D'Plácido, 2017. Naquele momento, busquei reconstruir criticamente as bases do imaginário social brasileiro no que diz respeito a uma narrativa do atraso nacional (desqualificadora da política e das lutas por reconhecimento no Brasil) e seus impactos para a "nossa" teoria constitucional. Nessa mesma linha de uma reconstrução crítica da teoria constitucional brasileira, ver também o artigo: GOMES, David Francisco Lopes. Para uma crítica à tese da constitucionalização simbólica. Revista Eletrônica do Curso de Direito da UFSM, Santa Maria, RS, v. 12, n. 2, p. 442-471, ago. 2017. ISSN 1981 3694. Disponível em: https://periodicos.ufsm.br/revistadireito/article/view/24821 . Acesso em: 02 abr. 2018. doi: http://dx.doi.org/10.5902/1981369424821.
} 
A tarefa no presente texto será de apresentar, à luz das reflexões de Honneth, as críticas e os limites acerca de uma teoria da justiça liberal, ao demonstrar que a textura da justiça está ancorada em relações sociais intersubjetivamente reconhecidas que são constituídas de práticas perpassadas de conteúdo moral. Para tanto, analisa-se, num primeiro momento, os componentes de uma teoria liberal da justiça, a partir da influência do pensamento de John Rawls. Feito isso, submete-se os pilares do liberalismo a um exame crítico. Num terceiro momento, apresenta-se o percurso de Honneth em direção a uma atualização indireta da filosofia de Hegel, a fim de traçar um esboço do seu modelo normativo alternativo, expondo as possíveis respostas às limitações e insuficiências da matriz liberal da justiça. Desse modo, espera-se repensar a justiça para além de uma dimensão abstrata, de modo a colocar em evidência a necessidade de reconstrução crítica dos fragmentos de normas e princípios morais e políticos já inscritos, ainda que parcialmente, na própria realidade social.

Feita essa exposição geral da estrutura do artigo, assim como o problema sobre o qual se investiga e o objetivo que se propõe, o percurso metodológico que aqui se desenha é o de uma pesquisa fundamentalmente bibliográfica de vertente teórico-filosófica, tendo como pano de fundo o referencial da hermenêutica e da teoria crítica.

\section{BASES DE UMA TEORIA LIBERAL DA JUSTIÇA}

A versão mais visível e influente de uma teoria liberal da justiça, dominante nos dias atuais, é a formulação de John Rawls ${ }^{10}$. Qual o objeto e a finalidade de uma teoria da justiça; como definir as liberdades básicas dos cidadãos e conciliá-las com a igualdade democrática; qual a distribuição mais apropriada dos bens sociais básicos (liberdades, renda e riqueza, oportunidades, bem-estar, auto respeito); como justificar os princípios que devem orientar a configuração das instituições públicas de uma sociedade justa; como o debate público político deve estar estruturado de modo a incluir a diversidade de interesses e valores; como conciliar os direitos subjetivos individuais e o ideal do bem comum, são algumas das questões levantadas pela teoria de Rawls e que pautam (positivamente ou negativamente) a agenda de discussão há pelo menos quatro décadas. ${ }^{11}$

\footnotetext{
${ }^{10}$ HONNETH, Axel; ANDERSON, Joel. Autonomia, Vulnerabilidade, Reconhecimento e Justiça. Cadernos de Filosofia Alemã: crítica e modernidade. São Paulo, XVII, jan.-jun. 2011. p.101

11 WERLE, Denílson Luis. A ideia de justiça e a prática da democracia. Novos estudos CEBRAP 92, São paulo Mar. 2012: 153.
} 
Rawls constrói uma teoria da justiça como equidade que tem como objeto primário a estrutura básica da sociedade ou, mais precisamente, "a maneira pela qual as instituições sociais mais importantes distribuem direitos e deveres fundamentais e determinam a divisão de vantagens decorrentes da cooperação social"12. Essa concepção de justiça distributiva estaria ancorada em três pressupostos, quais sejam a escassez moderada de recursos, em razão da situação de que os bens a distribuir são limitados; o reconhecimento do "fato do pluralismo", que conduz à existência de um desacordo profundo acerca das concepções de vida boa; e, ainda, o reconhecimento dos sujeitos como seres dotados de racionalidade e razoabilidade, pois aptos a construir seu próprio projeto de vida e a desenvolver um "sentido de justiça". ${ }^{13}$

Com base nesses pressupostos, Rawls ${ }^{14}$ simula um contexto deliberativo fictício para pensar a formulação de princípios de justiça universalmente aceitáveis a partir de um ponto de vista imparcial. 0 autor pede que imagine-se uma "posição original”, na qual os sujeitos livres e iguais teriam a chance de deliberarem acerca dos princípios fundamentais de justiça da sociedade. "Essa posição original não é, obviamente, concebida como uma situação histórica real, muito menos como uma condição primitiva da cultura. É entendida como uma situação puramente hipotética caracterizada de modo a conduzir a uma certa concepção da justiça”15.

Esses sujeitos, na formulação de Rawls ${ }^{16}$, precisariam estar submetidos ao "véu da ignorância", como uma forma de garantir que aqueles que procuram chegar a um acordo sobre princípios que governam sua cooperação equitativa não tenham qualquer conhecimento sobre seus talentos e posições sociais ${ }^{17}$, de forma que "ninguém conhece seu lugar na sociedade, a posição de sua classe ou o status social e ninguém conhece sua sorte na distribuição de dotes e habilidades naturais, sua inteligência, força e coisas semelhantes”18.

Tal procedimento imaginário seria uma simulação de imparcialidade ao garantir que a deliberação se desenvolva em função apenas de considerações gerais sobre uma sociedade justa, e não em função de interesses egoístas. Nos termos de Rawls, “uma vez que todos estão numa situação de semelhante e ninguém pode designar princípios para favorecer sua condição particular, os princípios da justiça são o resultado de um consenso ou ajuste equitativo"19.

\footnotetext{
12 RAWLS, John. Uma teoria da justiça. 2. ed. São Paulo: Martins Fontes, 2002. p. 8.

${ }^{13}$ RAWLS, John. O liberalismo político. 2. ed. São Paulo: Ática, 2000.

${ }^{14}$ RAWLS, John. Uma teoria da justiça. 2. ed. São Paulo: Martins Fontes, 2002. p. 13.

${ }^{15}$ RAWLS, John. Uma teoria da justiça. São Paulo: Martins Fontes, 1997. p. 04.

${ }^{16}$ RAWLS, John. 0 liberalismo político. 2. ed. Trad. Dinah de Abreu Azevedo. São Paulo: Ática, 2000.

17 HONNETH, Axel; ANDERSON, Joel. Autonomia, Vulnerabilidade, Reconhecimento e Justiça. Cadernos de Filosofia Alemã: crítica e modernidade. São Paulo, XVII, jan.-jun. 2011. p. 102.

${ }^{18}$ RAWLS, John. Uma teoria da Justiça. São Paulo: Martins Fontes, 1997, p. 13.

19 RAWLS, John. Uma teoria da Justiça. São Paulo: Martins Fontes, 1997, p. 13.
} 
Os princípios da justiça de John Rawls, que se fundariam a partir da posição original, teriam como objetivo principal a sustentação da estrutura básica da sociedade, para que, num esquema de cooperação, possa ordenar as instituições, contendo diretrizes básicas para que estas possam promover os valores de liberdade e igualdade, os quais são peremptórios em uma sociedade que percebe que os cidadãos são iguais e livres $^{20}$. Os princípios seriam, então, deduzidos de um procedimento abstrato e imparcial de forma a possibilitar o respeito às multifacetadas concepções de bem. Como consequência da posição original surgiriam três princípios distributivos: o da igual liberdade para todos, o da diferença e o da igualdade de oportunidades. Nos termos de Rawls, eis os princípios de justiça:

\begin{abstract}
a) todas as pessoas têm igual direito a um projeto inteiramente satisfatório de direitos e de liberdades básicas iguais para todos, projeto este compatível com todos os demais; e, neste projeto, as liberdades políticas, e somente estas, deverão ter seu valor equitativo garantido.

b) as desigualdades sociais e econômicas devem satisfazer dois requisitos: primeiro, devem estar vinculadas a posições e cargos abertos a todos,

c) em condições de igualdade equitativa de oportunidades; e, segundo, devem representar o maior benefício possível aos membros menos privilegiados da sociedade ${ }^{21}$.
\end{abstract}

Essa formulação de Rawls é muito importante para o pensamento político, especialmente porque ele é o responsável por colocar em pauta a reconstrução de uma teoria da justiça para o tempo presente, influenciando profundamente a matriz liberal contemporânea. Tal matriz está tão arraigada no pensamento político a ponto de parecer existir certo consenso no que diz respeito ao modo como devem ser constituídas as premissas de uma teoria da justiça social. De modo geral, essa concordância está sustentada na ideia de que os princípios de justiça devem ser expressão da vontade comum de todos os cidadãos de assegurar reciprocamente as mesmas liberdades subjetivas de ação ${ }^{22}$.

No interior desse princípio abstrato, convivem duas concepções de justiça social que compõem a teoria liberal dominante. A primeira é a de que a justiça social deve ser avaliada com base no grau de realização da autonomia pessoal. A segunda consiste na ideia de que os princípios de justiça devem ser passíveis de ser concebidos como resultado de uma formação

20 ZAMBAM, Neuro José. John Rawls e a educação para a democracia. Argumentos-Revista de Filosofia, v. 2018, n. 19., P. 133.

${ }^{21}$ RAWLS, John. O liberalismo político. 2. ed. Trad. Dinah de Abreu Azevedo. São Paulo: Ática, 2000, p. 47.

22 HONNETH, Axel. A textura da justiça: sobre os limites do procedimentalismo moderno. Civitas, Porto Alegre, v.9, n.3, set.-dez. 2009. p. 348. 
comum da vontade. ${ }^{23}$ De um lado, está a garantia igual da autonomia individual; de outro, o modo de geração dos princípios da justiça.

$\mathrm{Na}$ primeira concepção, é possível entrever um dos principais compromissos do liberalismo que é o de salvaguardar a autonomia dos indivíduos, assegurando-lhes condições para que possam perseguir suas preferências pessoais e seus próprios planos de vida. Essa noção de autonomia está ancorada numa concepção segundo a qual a liberdade do indivíduo será maior quanto menores forem as limitações por parte dos outros. Aqui, pois, surge a ideia transcendente de que a criação de relações sociais justas deve servir primeiramente à finalidade de possibilitar a todos os sujeitos, igualmente, uma forma de autodeterminação que os permita ser tão independentes de seus parceiros de interação quanto possível ${ }^{24}$. A principal implicação disso é o surgimento do paradigma distributivo: a tarefa da justiça, então, seria assegurar uma distribuição equânime de bens de modo que cada um possa buscar, com independência, sua própria concepção de vida boa.

Já na segunda concepção, é reivindicado um procedimento por meio do qual devem ser elaborados os princípios normativos de justiça a partir de uma formação comum da vontade de todos os cidadãos. Uma vez que os membros da sociedade liberal devem, a princípio, ser concebidos como livres e autodeterminados, a distribuição dos bens, para ser considerada justa, deve partir de um experimento mental de um contrato ou de uma situação de deliberação que permita chegar a conclusões justificadas sobre qual tipo de distribuição de bens os cidadãos prefeririam $^{25}$. Instaura-se, nessa situação, um procedimento deliberativo, abstraído das condições reais da práxis política, que possibilita selecionar, com imparcialidade, aqueles princípios distributivos de justiça de igual interesse para todos.

Convivem, portanto, na teoria liberal da justiça, fortemente influenciada pelo pensamento de Rawls, dois componentes: um material-distributivo que pretende assegurar as condições para a realização da autonomia individual, entendida numa dimensão subjetivista, e outro procedimental, que visa assegurar, por meio de uma cooperação voluntária, a justificação dos princípios de justiça e os modos de distribuição mais equânimes. Mas há ainda um terceiro componente, segundo Honneth, que funcionaria como base da teoria da justiça dominante: trata-se da agência ou da instância responsável por implementar, na realidade social, os

${ }^{23}$ HONNETH, Axel. A textura da justiça: sobre os limites do procedimentalismo moderno. Civitas, Porto Alegre, v.9, n.3, set.-dez. 2009. p. 348

${ }^{24}$ HONNETH, Axel. A textura da justiça: sobre os limites do procedimentalismo moderno. Civitas, Porto Alegre, v.9, n.3, set.-dez. 2009. p. 349

${ }^{25}$ HONNETH, Axel. A textura da justiça: sobre os limites do procedimentalismo moderno. Civitas, Porto Alegre, v.9, n.3, set.-dez. 2009. p. 351 
princípios distributivos tidos como justificados ${ }^{26}$. Na teoria da justiça dominante, é o Estado a única agência correspondente de efetivação da justiça, pois é só ele que dispõe de meios legítimos para impor efetivamente as medidas necessárias para a redistribuição.

Apresentados os três componentes que integram a matriz liberal da justiça ${ }^{27}$, o próximo passo da investigação em curso passa a ser submeter, à luz das reflexões de Honneth, cada um desses elementos mencionados a um exame crítico.

\section{UMA ANÁLISE CRÍTICA DOS ELEMENTOS DE UMA TEORIA LIBERAL DA JUSTIÇA}

O primeiro elemento da matriz liberal, como vimos, é a distribuição equitativa de bens básicos como modo de assegurar a autodeterminação individual e produzir uma ordem social justa. Parece clara a ideia de que a liberdade depende, necessariamente, de meios e chances para a realização autônoma de escolhas: "recursos financeiros abrem-nos uma variedade de opções em nossa vida, um espectro amplo de ofertas de trabalho nos permite a realização determinada de nossas habilidades" ${ }^{28}$. No entanto, no interior dessas formulações já existe algo pressuposto que, à primeira vista, é difícil de identificar dentro do esquema distributivo. Para que uma pessoa possa perceber que o dinheiro abre a possibilidade de liberdade, ela precisa, antes de tudo, ter objetivos dignos de serem alcançados; para que uma outra possa compreender as chances profissionais como caminhos para realização de suas habilidades individuais, ela precisa, primeiro, ter compreendido suas habilidades e talentos como importantes e dignos de realização ${ }^{29}$. 0 primeiro problema da formulação liberal, identificado

${ }^{26}$ HONNETH, Axel. A textura da justiça: sobre os limites do procedimentalismo moderno. Civitas, Porto Alegre, v.9, n.3, set.-dez. 2009. p. 352

${ }^{27}$ Embora não seja o objetivo do presente texto analisar especificamente categorias de Rawls como "razão pública" e "desacordo razoável", necessário se faz ressaltar que o autor, "após as polêmicas e discussões acerca da sua obra Uma Teoria da Justiça, nas décadas seguintes publicou outras obras em que pretendeu esclarecer alguns pontos de sua abordagem, inserindo a questão da esfera pública na obra Liberalismo Político (1993), internacionalizando a sua perspectiva na obra O Direito dos Povos (1999), e, também lançou as obras História da Filosofia Moral (2000) e Justiça como Equidade (2001)". FONSECA, Maria Fernanda Soares; FERREIRA, Maria da Luz Alves. As Teorias da Justiça: um contraponto entre as concepções de John Rawls e Robert Nozick. Revista Eletrônica do Curso de Direito da UFSM, v. 11, n. 2, p. 601-617, 2016.

${ }^{28}$ HONNETH, Axel. A textura da justiça: sobre os limites do procedimentalismo moderno. Civitas, Porto Alegre, v.9, n.3, set.-dez. 2009. p. 352

29 HONNETH, Axel. A textura da justiça: sobre os limites do procedimentalismo moderno. Civitas, Porto Alegre, v.9, n.3, set.-dez. 2009. p. 352 
por Honneth, é de que os pressupostos necessários para a autodeterminação individual não são “coisas" a serem distribuídas, mas algo além, que só pode ser conquistado através das relações entre as pessoas.

O que está no centro desse primeiro problema do modelo liberal é justamente sua concepção equivocada de autonomia. Nenhuma lista de bens básicos, por mais ampla e bem pensada, pode dizer o que, de fato, deveria ser concedido para que um sujeito tenha plenas condições para o exercício de sua autonomia. Apenas se alcança a autonomia por meio de relações intersubjetivas, pois aprende-se, através do reconhecimento com o outro, a compreenderem-se como seres cujas necessidades, convicções e habilidades são dignas de serem realizadas.

Por isso, "só compreendemos em nós se ao mesmo tempo o concedemos àquelas pessoas que nos reconhecem, porque devemos poder reconhecer, como em um espelho, nosso próprio valor no comportamento delas com relação a nós"30. A autonomia, pois, é uma dimensão relacional, intersubjetiva, e não uma conquista monológica, algo que pode ser adquirido sozinho a partir de certos bens, como sugere o modelo distributivo. Ao invés de falar de bens, deve-se falar de relações de reconhecimento.

Esse deslocamento de um modelo distributivo para um de reconhecimento recíproco afetará o segundo componente da teoria liberal da justiça, qual seja, o recurso ao procedimento fictício. Para que seja preservada a ficção da geração autônoma de princípios de justiça, o material de justiça necessitaria ser pensado segundo o modelo de uma matéria disponível, algo que possa ser subdividido e distribuído. No entanto, se não é mais possível pensá-lo na forma de coisas a serem alocadas como condição da autonomia, mas como relações sociais recíprocas, então não faz o menor sentido o próprio procedimento fictício, já que não se está diante de algo que possa ser disposto livremente segundo convicções próprias de justiça ${ }^{31}$.

Sendo assim, o procedimento não tem como ser pensado de modo abstrato, como um experimento mental, mas sim como um acontecimento real, palpável, que ocorre na esfera pública democrática e que está ancorado nas diversas formas de vidas e nas compreensões dos sujeitos reais intersubjetivamente constituídas nas relações sociais.

O último pilar da teoria liberal da justiça, pode-se dizer, será igualmente afetado com a desconstrução dos dois primeiros. Trata-se, como visto, de conceber o Estado de Direito como a

\footnotetext{
${ }^{30}$ HONNETH, Axel. A textura da justiça: sobre os limites do procedimentalismo moderno. Civitas, Porto Alegre, v.9, n.3, set.-dez. 2009. p. 35

31 HONNETH, Axel. A textura da justiça: sobre os limites do procedimentalismo moderno. Civitas, Porto Alegre, v.9, n.3, set.-dez. 2009. p. 356
} 
única instância que dispõe dos meios adequados, geralmente aceitos, para implementar na sociedade os princípios de justiça tidos como justificados: por meio dos direitos protegidos por sanções, ele impõe de cima para baixo uma distribuição de bens básicos segundo o modelo que teria sido acordado anteriormente pelos atores sociais na deliberação fictícia ${ }^{32}$. A dificuldade de reafirmar a centralidade do Estado é apontada por Honneth a partir da própria concepção de que a autonomia só se constrói com base nas relações intersubjetivas.

Embora a comunidade jurídica exija que cada um reconheça reciprocamente o outro como cidadão livre e igual, existem outras esferas intersubjetivas de reconhecimento ${ }^{33}$ que não são tocadas diretamente pela força da lei, como as relações de família e de trabalho, nas quais os sujeitos adquirem outros meios de construir sua autoestima. Partindo da noção de Foucault de que o poder é resultado de instâncias diversas, descentralizadas e desarticuladamente conectadas, Honneth ${ }^{34}$ acredita que a justiça social é conquistada e assegurada por muitas agências atuantes que se movem num terreno pré-estatal, como os grupos de autoajuda, os sindicatos, as comunidades eclesiásticas ou outros agrupamentos civis. 0 fato de não conseguir perceber as atividades das organizações civis e instituições não-estatais como intervenções morais, como incentivadoras sociais da justiça, é consequência do modo de ver limitado colocado pelas teorias da justiça hoje dominantes.

\section{O MODELO ALTERNATIVO DE HONNETH: NO CAMINHO DE UMA REATUALIZAÇÃO INDIRETA DA FILOSOFIA DE HEGEL}

Todas as críticas acerca dos elementos da matriz liberal parecem ser consequência de um déficit sociológico, expresso na sua incapacidade de oferecer um vínculo consistente entre teoria da justiça e um diagnóstico crítico das condições reais e intersubjetivas para a autodeterminação individual, que seja capaz de apontar ao mesmo tempo para a superação das deficiências e patologias sociais. De certo modo, a oposição criada entre "o que é" e "o que deve ser" é resultado do desenvolvimento teórico da teoria da justiça dominante que se desligou da ideia de eticidade tal como concebida por Hegel.

32 HONNETH, Axel. A textura da justiça: sobre os limites do procedimentalismo moderno. Civitas, Porto Alegre, v.9, n.3, set.-dez. 2009. p. 357.

33 HONNETH, Axel. Luta por reconhecimento: a gramática moral dos conflitos sociais. São Paulo: 34, 2003.

34 HONNETH, Axel. A textura da justiça: sobre os limites do procedimentalismo moderno. Civitas, Porto Alegre, v.9, n.3, set.-dez. 2009. p. 345-368. 
Uma teoria da justiça deveria satisfazer as exigências normativas presentes nos padrões de reconhecimento recíproco ou, em outros termos, a autorrealização individual deveria ser assegurada por uma estrutura de direitos, liberdades e deveres - como querem os "liberais" -, mas que não fosse abstratamente deduzida, e sim efetivada num contexto ético intersubjetivamente compartilhado - como defendem os "comunitaristas" 35 . É nesse sentido que Honneth procurará desenvolver, com base na atualização da filosofia de Hegel, uma teoria da justiça ligada não a modelos abstratos, mas a uma reconstrução das práticas e normas de reconhecimento já institucionalizadas.

No entanto, esse empreendimento de uma releitura de Hegel no contexto da sociedade atual esbarra em sérios problemas, especialmente no significado que sua obra "Filosofia do Direito" passou a receber na discussão político-filosófica contemporânea. Falamos propriamente, por um lado, da desconfiança do teor antidemocrático de sua obra, uma vez que os direitos de liberdade individual seriam, na perspectiva hegeliana, subordinados à autoridade ética do Estado; e, por outro, da reserva no que diz respeito ao papel fundamental de sua "Lógica" no sentido que só seria possível compreender sua filosofia do direito no sistema. ${ }^{36}$

Com base na história dos possíveis efeitos da filosofia de Hegel, Honneth ${ }^{37}$ decide, então, percorrer o caminho de uma atualização indireta da obra "Filosofia do Direito", prescindindo do seu conceito substancialista de Estado e das instruções operativas de sua Lógica. Isso ocorre, especialmente, porque a virada linguística, a pluralização das formas de vida e as exigências de um pensamento pós-metafísico levaram a uma necessidade crescente de um aprofundamento de análise social em detrimento do idealismo hegeliano.

Apesar de compreender os riscos inerentes a um processo de atualização indireta desse tipo - que poderia descontextualizar de tal modo a obra de Hegel que ela acabaria perdendo o seu sentido como um todo ou mesmo as intuições mais relevantes -, Honneth acredita ser possível manter-se fiel ao pensamento de Hegel ao reavivar pelo menos dois conceitos chaves da "Filosofia do Direito": o "espírito objetivo" e a "eticidade". Esses dois conceitos que pretendemos agora analisar são fundamentais para a construção da teoria da justiça tal como pensada por Honneth, como modelo alternativo à teoria liberal dominante.

35 WERLE; Denilson Luis; MELO, Rúrion Soares. Introdução: Teoria crítica, teorias da justiça e a "reatualização" de Hegel. In: HONNETH, Axel. Sofrimento de Indeterminação. Uma reatualização da filosofia do direito de Hegel. São Paulo: Editora Singular, Editora Esfera Pública, 2007. p.31

${ }^{36}$ HONNETH, Axel. Sofrimento de Indeterminação. Uma reatualização da filosofia do direito de Hegel. São Paulo: Editora Singular, Editora Esfera Pública, 2007, p.48-49

${ }^{37}$ HONNETH, Axel. Sofrimento de Indeterminação. Uma reatualização da filosofia do direito de Hegel. São Paulo: Editora Singular, Editora Esfera Pública, 2007. 
0 primeiro elemento teórico, qual seja o espírito objetivo, consiste numa parte da filosofia de Hegel que tinha por objeto os princípios normativos de uma ordem social justa sob condições modernas. Para Honneth, tal elemento parece conter a tese de que "toda realidade social possui uma estrutura racional"38. Essa noção implica a ideia de que as instituições e práticas sociais estão ancoradas em fundamentos racionais que, na hipótese de serem violados, conduzem a danos e patologias sociais. Essa dimensão racional das instituições e práticas sociais desvela a existência de uma certa consonância entre tais práticas e instituições e os sujeitos que a compõem.

O “espírito objetivo", à luz da releitura que faz Honneth, corresponderia, na própria racionalidade já presente e manifesta em mentalidades e tradições, a normas e valores ${ }^{39}$. Sob as condições da modernidade, o "espírito objetivo" assumiria a forma da "vontade livre universal", no sentido de apontar a necessidade de uma reconstrução das condições sociais e percursos necessários para a realização da autonomia individual de cada homem. Como consequência, os princípios normativos de liberdade comunicativa na sociedade moderna não estão ancorados em preceitos voltados para o comportamento ou em meras leis de coerção, mas estão atrelados ao exercício prático, presente nos padrões habituais da ação e dos costumes, que já contém em si uma estrutura racional. ${ }^{40}$

O segundo elemento chave para uma atualização indireta de Hegel, aquele da "eticidade", corresponde a um conjunto de práticas e instituições constitutivas de uma socialização compartilhada intersubjetivamente e responsáveis pela construção de nossos valores, motivações e interesses. Nesse sentido, a esfera de eticidade abrange "uma série de ações intersubjetivas nas quais os sujeitos podem encontrar tanto a realização individual quanto o reconhecimento mútuo" ${ }^{41}$. Essas ações intersubjetivas têm uma dimensão normativa, pois podem ser representadas num tipo de interação na qual os sujeitos consideram reciprocamente as normas, mas sem senti-las como um dever.

Há, portanto, uma normatividade implícita que está inscrita, ainda que parcialmente, nas próprias práticas e instituições sociais, apta a fomentar processos de aprendizado que desenvolvem certas disposições comportamentais. As ações e comportamentos, assim como as

${ }^{38}$ HONNETH, Axel. Sofrimento de Indeterminação. Uma reatualização da filosofia do direito de Hegel. São Paulo: Editora Singular, Editora Esfera Pública, 2007, p. 51.

39 HONNETH, Axel. Sofrimento de Indeterminação. Uma reatualização da filosofia do direito de Hegel. São Paulo: Editora Singular, Editora Esfera Pública, 2007, p. 96.

${ }^{40}$ HONNETH, Axel. Sofrimento de Indeterminação. Uma reatualização da filosofia do direito de Hegel. São Paulo: Editora Singular, Editora Esfera Pública, 2007, p. 54.

${ }^{41}$ HONNETH, Axel. Sofrimento de Indeterminação. Uma reatualização da filosofia do direito de Hegel. São Paulo: Editora Singular, Editora Esfera Pública, 2007, p.110 
carências e inclinações, estão enraizados em padrões comunicativos e normativos de costume de tal modo que a identidade e a liberdade são apreendidas ao mesmo tempo que são aprendidas.

Juntos, os conceitos de "espírito objetivo" e "eticidade" parecem apontar para a construção de um modelo alternativo capaz de confrontar as teorias liberais da justiça mediante a tese de Honneth ${ }^{42}$, segundo a qual as relações sociais de vida já contêm suficientes normas capazes de serem fundamentadas e que podem suportar com segurança a maior parte dos juízos e decisões. Desse modo, não faz sentido a fundamentação de uma teoria ideal da justiça, mas uma teoria social da justiça, pois se está diante não da construção de "princípios normativos", mas da sua reconstrução na própria sociedade, de modo a revelar aqueles padrões de interação que podem efetivamente valer como condições imprescindíveis de realização da liberdade individual. Desse modo, já caminhando para o fim da análise, pretende-se oferecer, com base na atualização indireta da filosofia de Hegel, tal como pensada por Honneth, alternativas aos três elementos essenciais para a teoria da justiça dominante que serviram de fio condutor durante quase todo o percurso da exposição supra.

Primeiramente, no lugar de um modelo pautado na distribuição de bens, ainda ancorado numa compreensão da liberdade como algo que cada indivíduo pode alcançar por si próprio, coloca-se a concepção de uma inclusão de todos os sujeitos nas relações intersubjetivas de reconhecimento desenvolvidas em cada situação. Essas relações de reconhecimento, em distinção a bens, não são simplesmente passíveis de serem distribuídas aleatoriamente a potenciais beneficiários segundo regras fixas; trata-se de produtos históricos que assumiram a forma de práticas institucionais, nas quais os sujeitos estão incluídos ou das quais podem ser excluídos $^{43}$. As relações de reconhecimento, historicamente dadas, já pressupõem uma normatividade implícita que serve, num contexto temporal específico, de fonte de valorização de certas habilidades e de imputação de algumas condutas. O que isso coloca é a necessidade de se pensar a questão da inclusão do outro num contexto da concretude das relações nos processos de reconhecimento.

Num segundo momento, é preciso substituir a construção de um procedimento fictício gerador de princípios de justiça por uma reconstrução normativa que revele, históricogeneticamente, as normas morais fundamentais daquelas relações de reconhecimento ${ }^{44}$. Tendo

42 HONNETH, Axel. Sofrimento de Indeterminação. Uma reatualização da filosofia do direito de Hegel. São Paulo: Editora Singular, Editora Esfera Pública, 2007, p.115

43 HONNETH, Axel. A textura da justiça: sobre os limites do procedimentalismo moderno. Civitas, Porto Alegre, v.9, n.3, set.-dez. 2009, p. 351.

44 HONNETH, Axel. A textura da justiça: sobre os limites do procedimentalismo moderno. Civitas, Porto Alegre, v.9, n.3, set.-dez. 2009, p. 360. 
em vista que a matéria da justiça precisa ser pressuposta historicamente, é inútil recorrer à abstração de um experimento mental. Partir das relações de reconhecimento já existentes exige que a fundamentação dos princípios de justiça seja desvelada no processo histórico das próprias práticas e instituições concretas.

Ao contrário de uma construção normativa, a teoria da justiça tal como concebida por Honneth opera a partir de uma reconstrução normativa desses princípios já inscritos nas práticas sociais. No entanto, seu sentido não está em si determinado, mas se apresenta sempre aberto e insaturável a construções interpretativas. É nesse sentido que os percursos históricos das lutas por reconhecimento devem ser desvelados e retomados como forma de reconstrução, hoje, dos padrões normativos prevalecentes na sociedade ${ }^{45}$.

Num terceiro instante, faz-se imprescindível complementar o olhar exclusivo sobre a atividade reguladora do Estado de Direito por uma consideração descentralizada de agências, organizações e entidades não estatais. Esse empreendimento está arraigado na ideia de que existem diferentes e multifacetadas formas de reconhecimento social como necessárias para a realização da autonomia individual do que aquelas que podem ser garantidas pela participação em processos públicos de formação da vontade: os sujeitos necessitam da valorização e da consideração intersubjetivas também em papéis sociais que desempenham para além de suas atividades como sujeitos de direito ${ }^{46}$.

O direito constitui apenas numa das esferas intersubjetivas de reconhecimento, existindo outras, igualmente significativas, que permitem ao sujeito a experiência de ser valorizado em suas necessidades e habilidades. As relações familiares íntimas ${ }^{47}$ e as relações

\footnotetext{
45 Isso leva Honneth (HONNETH, Axel. Luta por reconhecimento: a gramática moral dos conflitos sociais. São Paulo: Editora 34, 2003, p. 262) a basear-se em dois pressupostos para delinear a gramática moral do conflito social. 0 primeiro estaria pautado na ideia de que a mola propulsora que conduz os sujeitos à revolta social está ancorada em sentimentos de injustiça e experiências de desrespeito. 0 segundo, como consequência do primeiro, revelar-se-ia na constatação de que o motor da história humana que está em constante processo dialético é a luta social. São, portanto, as experiências de negatividade o caminho social para a luta que movimenta o político para o estabelecimento de novos padrões normativos de reconhecimento. Diferentemente das teorias políticas de Hobbes, Maquiavel e Rousseau em que o conflito ocorre somente pela autoconservação material, o conflito é visto aqui como produtivo, pois é a partir dele que as transformações sociais são possíveis (HONNETH, Axel. Reconocimiento y obligaciones Morales. RIFP, 8, p. 5-17, 1996).

${ }^{46}$ HONNETH, Axel. A textura da justiça: sobre os limites do procedimentalismo moderno. Civitas, Porto Alegre, v.9, n.3, set.-dez. 2009, p. 364.

47 Sobre essa questão, Honneth entende que a primeira esfera de reconhecimento social é o amor, pois é nela que encontramos as relações primárias e mais íntimas do sujeito que são essenciais para a construção da confiança em si mesmo. É nesta esfera de reconhecimento que se identifica a "expressão afetiva de uma dedicação, que cria em todo ser humano o fundamento psíquico para poder confiar nos próprios impulsos carenciais" (HONNETH, Axel. Luta por reconhecimento: a gramática moral dos conflitos sociais. São Paulo: Editora 34, 2003, p.195). As relações familiares e os laços de amizade estariam nessa primeira
} 
sociais de trabalho precisam ser também tomadas como objeto a ser tematizado na teoria da justiça, pois são significativas por contribuírem para o sucesso ou fracasso da autodeterminação individual.

\section{CONCLUSÃO}

Chega-se à conclusão dessa exposição. A reconstrução dos elementos-chave da teoria de John Rawls possibilitou a identificação de alguns dos pilares da teoria liberal contemporânea que foram tomados como base de análise e crítica. Foi possível, com isso, apresentar, à luz das reflexões de Honneth, algumas insuficiências e limites de uma teoria da justiça liberal e alternativas a esse modelo.

A primeira proposta colocada foi a substituição da ideia liberal de distribuição abstrata de bens pela ideia de inclusão em relações concretas situadas de reconhecimento. A segunda foi a crítica da formulação teórica de um contrato social fictício como forma de pensar os princípios de justiça em favor da ideia de reconstrução normativa que retoma, historicamente, os princípios já inscritos nas próprias práticas e instituições sociais. E, por fim, a terceira proposta foi a de repensar o modelo normativo pautado quase que exclusivamente na figura do Estado pela consideração também de outras esferas de reconhecimento descentralizadas e não estatais.

As três propostas de Honneth, como uma alternativa ao pensamento liberal dominante, apontam, portanto, para uma possibilidade bem consistente de reformular a teoria da justiça enquanto análise de uma sociedade existente, sem, para isso, precisar recorrer a premissas normativistas abstratas desconectadas dos conflitos políticos e das reivindicações por direitos. Essa reformulação opera por meio da defesa de pretensões normativas socialmente sustentadas na concretude do mundo da vida e traduzidas em lutas por reconhecimento dos movimentos sociais.

Isso não significa apoiar-se na mera reprodução dos valores e tradições prevalecentes em uma sociedade, o que pressuporia replicar o conservadorismo também numa perspectiva teórica, nem mesmo significa a defesa de valores universais pressupostos como apoio crítico da realidade, mas tomar essa mesma realidade e suas experiências de sofrimento nas esferas íntimas, pessoais, interativas e políticas - que não são exclusivas do Estado - como objeto

etapa. As experiências negativas ligadas a essa esfera são os maus-tratos físicos ou moral, o que afeta tanto a confiança que o sujeito possui sobre o seu próprio corpo quanto a que possui em si mesmo como pessoa, o que influenciará fortemente nas suas habilidades e na realização de sua própria autonomia. 
privilegiado da crítica social. Há nessa reformulação um deslocamento que permite inserir, como ponto de partida da análise da política e das demais relações sociais, questões como o poder e as desigualdades.

O racismo, o machismo, a homofobia, bem como as práticas sociais que produzem e reforçam a violência de classe, são patologias sociais da razão moderna, tendo sido constituídos histórica e intersubjetivamente no contexto de relações reais de não reconhecimento, passíveis de serem pensadas e enfrentadas historicamente. Esse enfrentamento não parte, pois, de princípios de justiça pré-fixados, prontos para serem aplicados, como sugere a tradicional teoria liberal. Ao contrário, é por meio da retomada das memórias e dos percursos de lutas sociais por reconhecimento que se torna possível reconstruir os padrões normativos já presentes nas práticas e instituições da sociedade concreta, que podem ser apropriados de modo a fundamentar uma crítica consistente de uma normatividade que ainda hoje ratifica e naturaliza atitudes opressoras e excludentes.

O desafio das democracias contemporâneas não está, pois, precisamente na afirmação de princípios de justiça transcendentais, abstraídos das condições reais da vivência política, nem na distribuição equânime de bens selecionados de forma que cada um possa tornar-se tão independente quanto possível de seus parceiros de interação. 0 desafio está em afastar efetivamente a teoria da justiça de qualquer idealismo, de modo a reposicioná-la frente aos compromissos com a própria práxis política, a partir da tarefa de compreender que a construção da autonomia está situada nos mais complexos processos de reprodução social, num movimento de explicitação de seus princípios normativos implícitos, expostos nas lutas sociais e nas expectativas de justiça bloqueadas e massacradas ao longo da história.

O interessante é, então, liberar essas expectativas e promessas que não foram satisfeitas e incorporá-las às expectativas de hoje, para lhes dar um conteúdo, de forma que se possa cobrá-las aqui e agora. Certamente, encontra-se nessas proposições, de certo modo abertas por Honneth, a tarefa de um comprometimento continuado e alimentado por um processo de aprendizado social ético de longo prazo, que talvez só possa existir na própria dinâmica interna e conflitiva da democracia (constitucional ${ }^{48}$ ).

\footnotetext{
${ }^{48}$ Esse processo de aprendizado social de longo prazo coloca a importância de se reabrir o passado dos projetos abortados e dos direitos não cumpridos a fim de liberar dele sua carga de futuro, o que, por sua vez, reflete a coesão interna entre tempo e Constituição. Especificamente sobre essa questão, minha proposta é que as análises de Honneth sejam complementadas com uma hermenêutica crítica da consciência histórica, tal como concebida por Paul Ricoeur (RICOEUR, Paul. A memória, a história, o esquecimento. Trad. Alain François et al. Campinas: Editora UNICAMP, 2007). Sobre o assunto, ver COSTA JUNIOR, Ernane Salles da. Constituição, tempo e narrativa: da crise da aceleração das mudanças
} 
Expor esses limites da proposta liberal é fundamental, se, de fato, pretende-se atribuir à teoria algum papel de relevância social, alguma função que seja imanente aos conteúdos da vivência intersubjetivamente compartilhados de uma sociedade, e que seja, ao mesmo tempo, crítica às situações de invisibilidade e vulnerabilidade que impossibilitam a realização satisfatória da autonomia pessoal. Essa tarefa de tornar explícito o que está implícito em forma de fragmentos e rastros da prática social significa denunciar o déficit sociológico da teoria rawlsiana, através de um exercício hermenêutico de reconstrução dos sentidos da justiça pelas experiências sociais de injustiças dos silenciados da história, pois tais sentidos não estão fechados em si, definidos de uma vez por todas, mas permanecem abertos e insaturáveis a novas interpretações e a novas possibilidades de aprendizado no próprio processo de realização das liberdades em deliberações políticas concretas.

A tarefa, portanto, de responder à questão, colocada pela(s) teoria(s) da justiça, de como construir uma sociedade justa de pessoas livres e iguais que se reconhecem reciprocamente exige um trabalho que vai além da dicotomia ou mesmo contraposição entre ideal e real, entre teoria e prática, na medida em que leva a sério sua tensão constitutiva que se revela num debate crítico, aberto e reconstrutivo sobre como lidar com as exigências e reivindicações prático-normativas de reconhecimento no por vir da democracia.

\section{REFERÊNCIAS}

CATTONI DE OLIVEIRA, Marcelo Andrade. Notas Programáticas para uma Nova História do Processo de Constitucionalização Brasileiro. Revista da Faculdade de Direito UFPR, 2010, n. 51, p. 45-72.

COSTA, Sérgio; WERLE, Denilson Luís. Reconhecer as diferenças: liberais, comunitaristas e as relações raciais no Brasil: In: AVRITZER, Leonardo e DOMINGUES, José Maurício (orgs). Teoria social e modernidade no Brasil. Belo Horizonte: Ed. UFMG (2000).

COSTA JUNIOR, Ernane Salles da. Constitucionalismo do atraso. Belo Horizonte: D’ Plácido, 2017.

normativas ao seu enfrentamento. Revista Direitos Fundamentais \& Democracia. 2013, Jun 4;13(13):81106; e ver também CATTONI DE OLIVEIRA, Marcelo Andrade. Notas Programáticas para uma Nova História do Processo de Constitucionalização Brasileiro. Revista da Faculdade de Direito UFPR, 2010, n. 51, p. 4572. 
COSTA JUNIOR, Ernane Salles da. Constituição, tempo e narrativa: da crise da aceleração das mudanças normativas ao seu enfrentamento. Revista Direitos Fundamentais \& Democracia. 2013, Jun 4;13(13):81-106.

FRASER, Nancy. Reconhecimento sem ética. Lua Nova, v. 70, n. 1, p. 101-138, 2007.

GOMES, David Francisco Lopes. Para uma crítica à tese da constitucionalização

simbólica. Revista Eletrônica do Curso de Direito da UFSM, Santa Maria, RS, v. 12, n. 2, p. 442471, ago. 2017. ISSN 1981-3694. Disponível em:

https://periodicos.ufsm.br/revistadireito/article/view/24821. Acesso em: 02 abr. 2018. doi: http://dx.doi.org/10.5902/1981369424821.

HONNETH, Axel. A textura da justiça: sobre os limites do procedimentalismo moderno. Civitas, Porto Alegre, v.9, n.3, p. 345-368, set.-dez. 2009.

HONNETH, Axel; ANDERSON, Joel. Autonomia, Vulnerabilidade, Reconhecimento e Justiça . Cardernos de Filosofia Alemã: crítica e modernidade. São Paulo, XVII, jan.-jun. 2011.

HONNETH, Axel. Luta por reconhecimento: a gramática moral dos conflitos sociais. São Paulo: Editora 34, 2003.

HONNETH, Axel. Reconocimiento y obligaciones Morales. RIFP, 8, p. 5-17, 1996.

HONNETH, Axel. Sofrimento de Indeterminação. Uma reatualização da filosofia do direito de Hegel. São Paulo: Editora Singular, Editora Esfera Pública, 2007.

MACINTYRE, Alasdair. Justiça de Quem? Qual Racionalidade? São Paulo: Loyola, 1991.

FONSECA, Maria Fernanda Soares; FERREIRA, Maria da Luz Alves. As Teorias da Justiça: um contraponto entre as concepções de John Rawls e Robert Nozick. Revista Eletrônica do Curso de Direito da UFSM, v. 11, n. 2, p. 601-617, 2016.

RAWLS, John. O liberalismo político. 2. ed. São Paulo: Ática, 2000.

RAWLS, John. Uma teoria da justiça. São Paulo: Martins Fontes, 1997.

RAWLS, John. Uma teoria da justiça. 2. ed. São Paulo: Martins Fontes, 2002.

RICOEUR, Paul. A memória, a história, o esquecimento. Trad. Alain François et al. Campinas: Editora UNICAMP, 2007.

TAYLOR, Charles. As Fontes do Self. A Construção da Identidade Moderna. São Paulo: Loyola, 1997.

WALZER, Michael. Esferas da Justiça. Uma Defesa do Pluralismo e da Igualdade. São Paulo, Martins Fontes, 2003.

Werle, Denílson Luis. A ideia de justiça e a prática da democracia. Novos estudos CEBRAP 92, São paulo Mar. 2012: 153-161. 
WERLE; Denilson Luis; MELO, Rúrion Soares. Introdução: Teoria crítica, teorias da justiça e a "reatualização" de Hegel. In: HONNETH, Axel. Sofrimento de Indeterminação. Uma reatualização da filosofia do direito de Hegel. São Paulo: Editora Singular, Editora Esfera Pública, 2007.

ZAMBAM, Neuro José. John Rawls e a educação para a democracia. Argumentos-Revista de Filosofia, v. 2018, n. 19.

\section{COMO FAZER REFERÊNCIA AO ARTIGO (ABNT):}

COSTA JUNIOR, Ernane Salles da. A necessidade de reconhecimento e os limites de uma Teoria Liberal da Justiça. Revista Eletrônica do Curso de Direito da UFSM, Santa Maria, RS, v. 14, n. 2, e32105, maio./ago. 2019. ISSN 1981-3694. DOI: http://dx.doi.org/10.5902/1981369432105. Disponível em: https://periodicos.ufsm.br/revistadireito/article/view/32105 Acesso em: dia mês. ano.

Direitos autorais 2019 Revista Eletrônica do Curso de Direito da UFSM

Editores responsáveis: Rafael Santos de Oliveira e Angela Araujo da Silveira Espindola

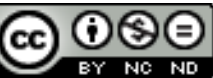

Este obra está licenciado com uma Licença Creative Commons Atribuição-NãoComercial-SemDerivações 4.0 Internacional.

\section{SOBRE O AUTOR}

\section{ERNANe SALLES dA COSTA JUNIOR}

Possui graduação em Direito pela Pontifícia Universidade Católica de Minas Gerais (2008), mestrado em Teoria do Direito com a distinção "Magna Cum Laude" pela mesma instituição (2011), doutorado no Programa de Pós-graduação da Universidade Federal de Minas Gerais (2016). Realizou residência pós-doutoral na UFMG em Direito Constitucional, sob a supervisão do professor titular Marcelo Cattoni, por doze meses, concluindo o programa em 2019. É também professor de Teoria do Direito e Direito Constitucional na Faculdade Promove, em Belo Horizonte. Realizou estágio doutoral com bolsa sanduíche da CAPES, no instituto "Fonds Ricoeur",em Paris, atuando na condição de pesquisador-associado e participando de seminários na École des Hautes Études en Sciences Sociales (EHESS), entre março a dezembro de 2015. Publicou 2 livros (um como autor e outro como coorganizador), 7 artigos completos em periódicos, 6 capítulos de livros, 5 trabalhos em anais de congressos (dentre os quais 3 são completos e 2 são resumos expandidos). Teve orientação concluída de 4 trabalhos de iniciação científica. Foi bolsista pelo CNPq no doutorado da UFMG e no mestrado da PUCMG e de iniciação científica pela FAPEMIG (2007) e PUCMG (2008). Atua nas áreas de Direito Constitucional, Sociologia e Filosofia do Direito, com ênfase nos seguintes temas: "Democracia e Constitucionalismo", "Identidade, Memória e Reconhecimento" e "Tempo, História e Direito". 